\title{
FRACTURE AND SIZE EFFECT STUDIES ON FIBRE REINFORCED SELF COMPACTING CONCRETE USING DIGITAL IMAGE CORRELATION
}

\author{
SANTOSH G. SHAH ${ }^{*}$, BHAVIN G. PATEL ${ }^{\dagger}$ AND ATUL K. DESAI ${ }^{\dagger \dagger}$ \\ Institute of Technology \& Management Universe \\ Vadodara, India \\ e-mail: santoshgshah@gmail.com \\ $\dagger$ S. V. National Institute of Technology \\ Surat, India \\ e-mail: bhavinpatel2000@gmail.com \\ ${ }^{\dagger}$ S. V. National Institute of Technology \\ Surat, India \\ e-mail: atuldesai61@gmail.com
}

Key words: Self Compacting Concrete, Size Effect, Fracture, Crack Opening, Digital Image Correlation

\begin{abstract}
The size effect and fracture behavior of plain and fiber-reinforced concrete was investigated. Geometrically similar beam specimens of different sizes with (steel fibers and glass fibers) and without fibers were tested under three-point bending in a closed loop servo-controlled machine with crack mouth opening displacement control with a rate of opening of $0.0005 \mathrm{~mm} / \mathrm{sec}$. The fracture properties such as, fracture energy $\left(\mathrm{G}_{\mathrm{f}}\right)$ and brittleness number were determined. Digital images were captured before loading (unreformed state) and at different instances of loading and were analyzed using correlation techniques to compute the load-point displacement, crack length, crack opening and crack tip location. It was seen that the crack mouth opening displacement (CMOD) and vertical load-point displacement computed using DIC analysis matches well with those measured experimentally. It also concluded that addition of fibers in specimens, increased energy absorption capacity tremendously in all size of specimens. It was observed that addition of fibers in concrete, brittleness number is decreased, hence the concrete becomes ductile. It was observed that the specimens follow the Bazant's size effect law which shows that the structure becomes brittle with increase in size.
\end{abstract}

\section{INTRODUCTION}

Self-compacting concrete (SCC) is a highperformance concrete that can flow under its own weight so as to completely fill the formwork and self-consolidate without any mechanical vibration [1-2]. This type of concrete is specifically designed to achieve excellent deformability, low risk of blockage, and good stability, ensuring a high formwork filling capacity. SCC is considered a suitable material for the construction of structural members with high volumes of steel reinforcement because of its ability to easily flow in highly congested areas [3-4].

Digital image correlation (DIC) has increasingly attracted attention in a variety of engineering areas like experimental mechanics 
[5-8], biomechanics [9-12] and geophysics [1314], owing to its well-known advantages in the aspect of full-field surface deformation measurements [15-20]. Electronic Speckle Photography (ESP) has been an active research area since the last two decades in which different parameters of the technique have been addressed for the improvement of accuracies in the measurement results and for the removal of different defects encountered during the experimentation. In ESP two images called reference (before the application of load) and test (after the application of load) images of an optically rough surface under illumination by a light source (e.g. a laser beam) are recorded. These two speckle images are correlated using DIC for measurement of in-plane displacements or deformations which the test image has under gone with respect to the reference image.

Considering the fact that the traditional DIC algorithm is usually so computationally intense that it is very difficult to meet some specified speed requirements for time critical applications or large-scale data processing tasks. On the other hand, some new numerical strategies such as basis function and sum-table methods have been developed to mathematically decrease the computational burden of DIC matching and hence increase the speed of integer-pixel correlation calculations to a great extent [11-12].

\subsection{Objectives of the present work}

The objectives of this study are.

- Development of plain and fiber reinforced self-compacting concrete.

- Monitoring of crack propagation using DIC technique.

- Measurement of beam deflection and crack width with the help of DIC technique.

\subsection{Principles of DIC}

Digital image correlation (DIC) is an optical and noncontact measurement technique and is adopted to analyze the displacements on the surface of an object of interest. In digital image correlation, the surface images before and after the deformation are taken by a digital camera from which the displacement at any point of the image is computed. DIC is extensively used to study a very large range of materials, in widely different range of scales. Originally developed in the 1980s [21-22].

DIC is based on the following principles: the image of the body is described by a discrete function representing the grey level of each pixel. The grey level is a value between 0 and 255 of its grey levels with the lowest value representing black, highest value white, and values in between representing different shades of gray. The correlation calculations are carried out for a set of pixels, called a pattern. The displacement field is assumed to be homogeneous inside a pattern. The initial image representing the body before distortion is a discrete function $\mathrm{f}(\mathrm{x}, \mathrm{y})$ and is transformed into another discrete function $\mathrm{f}^{*}\left(\mathrm{x}^{*}, \mathrm{y}^{*}\right)$ after distortion or displacement. The theoretical relation between the two discrete functions can be written as [23]:

$f^{*}\left(x^{*}, y^{*}\right)-f(x+u(x, y), y+v(x, y))=0$

where, $\mathrm{u}(\mathrm{x}, \mathrm{y})$ and $\mathrm{v}(\mathrm{x}, \mathrm{y})$ represent the displacement field for a pattern as shown in Figure 1.

Image correlation now becomes a job of comparing subsets of numbers between the two digital images. A typical cross correlation coefficient which measures how well subsets match is given by

$$
C=1-\frac{\sum\left[f(x, y) \cdot f^{*}\left(x^{*}, y^{*}\right)\right]}{\left[\sum\left(f(x, y)^{2}\right) \cdot \sum f^{*}\left(x^{*}, y^{*}\right)^{2}\right]^{1 / 2}}
$$

where $\mathrm{f}(\mathrm{x}, \mathrm{y})$ is the gray level value at coordinate $(x, y)$ for initial image and $f^{*}\left(x^{*}, y^{*}\right)$ is the gray level value at point $\left(\mathrm{x}^{*}, \mathrm{y}^{*}\right)$ of the deformed image. The coordinates $(\mathrm{x}, \mathrm{y})$ and $\left(\mathrm{x}^{*}\right.$, $\left.\mathrm{y}^{*}\right)$ are related by the deformation which has occurred between acquisition of the two images. If the motion of the object relative to the camera is parallel to the image plane, then they are related by;

$$
\begin{aligned}
& x^{*}=x+u+\frac{\partial \mathrm{u}}{\partial \mathrm{x}} \Delta x+\frac{\partial \mathrm{u}}{\partial \mathrm{y}} \Delta \\
& y^{*}=y+v+\frac{\partial \mathrm{v}}{\partial \mathrm{x}} \Delta x+\frac{\partial \mathrm{v}}{\partial \mathrm{y}} \Delta y
\end{aligned}
$$


where $\mathrm{u}$ and $\mathrm{v}$ are the displacements for the subset centers in the $\mathrm{x}$ and $\mathrm{y}$ directions, respectively. The terms $\Delta \mathrm{x}$ and $\Delta \mathrm{y}$ are the distances from the subset center to point $(\mathrm{x}, \mathrm{y})$. By performing image correlation, the values of coordinates $(\mathrm{x}, \mathrm{y})$, displacement $(\mathrm{u}, \mathrm{v})$, and the derivatives of the displacements $\partial \mathrm{u} \partial \mathrm{x}, \partial \mathrm{v} \partial \mathrm{y}$, $\partial \mathrm{v} / \partial \mathrm{x}$, and $\partial \mathrm{v} / \partial \mathrm{y}$ can be determined $[23,24]$. These are in turn used for further analysis, for example, in the computation of fracture parameters.

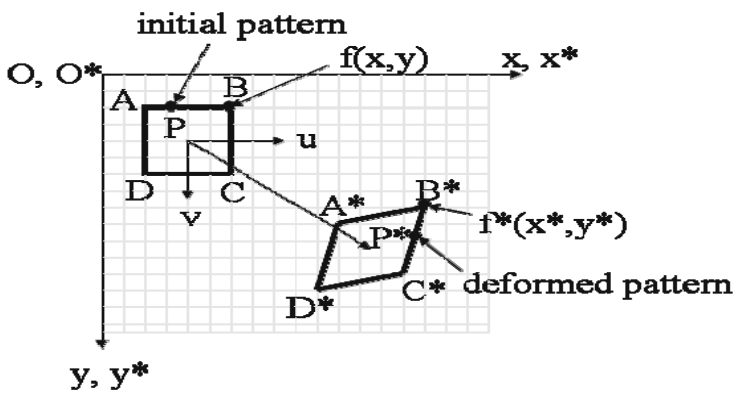

Figure 1: Initial and deformed patterns

\section{EXPERIMENTAL RESEARCH}

\subsection{Constitute materials}

A list of materials used for this study is given in Table 1 along with their specification. The physical properties of the sand and aggregates are given in Table 2.

\subsection{Mix proportions}

To achieve, self-capability, numbers of trail was done for different combination of materials. Binder contents varies between $450-700 \mathrm{~kg} / \mathrm{m}^{3}$ and Water/Binder $(\mathrm{W} / \mathrm{B})$ ratios varies between 0.29 to 0.34 ( by weight) with corresponding variation in the paste volume to investigate the influence of binder. The aggregate combination of 50:20:30 (Fine aggregate: Coarse aggregate $10 \mathrm{~mm}$ maximum size: Coarse aggregate $20 \mathrm{~mm}$ maximum size) by volume was kept constant for all mixes.

A polycarboxylate-based high range water reducing admixture (HRWRA) was also used in the mixtures; dosage of superplasticiser was kept constant at $0.5 \%$ by weight of binder for providing the desired fluidity of the SCC. For all tests, the proportion of cement to fly ash was kept constant. (Cement: Fly ash $=70: 30$ ). The final mixes are presented in Table 3.
Fiber reinforced self-compacting concrete (FRSCC) was achieved by adding steel fiber (Dramix RCBN 35/65 hooked end) and glass fibres (Cem-FIL) in selected mix proportion of concrete. The steel fiber has a diameter of 0.55 $\mathrm{mm}$, a length of $65 \mathrm{~mm}$, and a tensile strength of 1000-1100 N/mm ${ }^{2}$. CEM-FILL anti crack, high dispersion, alkali resistance glass fiber of diameter 17 micrometer and $12 \mathrm{~mm}$ length was used. A number of trials was conducted with different dosages of fibers to achieve steel fiber reinforced self-compacting concrete (SFRSCC) and glass fiber reinforced self-compacting concrete (GFRSCC). The content of $32 \mathrm{~kg} / \mathrm{m}^{3}$ steel fibers and $50 \mathrm{gm}$ per bag of cement glass fibers in self-compacting concrete satisfied the workability tests. Fresh and harden properties of plain and fiber reinforced self-compacting concrete are presented in Table 5 and Table 6 , respectively.

Table 1: Material used and their specifications

\begin{tabular}{|c|c|}
\hline Material & Specification \\
\hline $\begin{array}{l}\text { Ordinary } \\
\text { Portland cement }\end{array}$ & $\begin{array}{l}\text { As describe in IS: } 12269 \text {, } \\
\text { specific gravity }=3.12\end{array}$ \\
\hline Fly ash & $\begin{array}{l}\text { Dark, pozzocrete } 60 \\
\text { confirming to IS: } 3812 \text { (Part } \\
\text { 1) } 2013 \text {, Specific gravity }= \\
2.0\end{array}$ \\
\hline Superplasticiser & $\begin{array}{l}\text { Master Glenium SKY 8276, } \\
\text { BASF confirming ASTM C } \\
494\end{array}$ \\
\hline Fine aggregate & $\begin{array}{l}\text { Locally available river sand } \\
\text { passing through } 4.75 \mathrm{~mm} \text { IS } \\
\text { sieve confirming to IS: } 3812 \\
\text { (Part 1) } 2013\end{array}$ \\
\hline Coarse aggregate & $\begin{array}{l}\text { Locally available crushed } \\
\text { granite }- \text { maximum sizes } 20 \\
\text { mm and } 10 \text { mm confirming to } \\
\text { IS: } 3812 \text { (Part 1) } 2013\end{array}$ \\
\hline
\end{tabular}

\subsection{Specimen preparation}

The details of the geometry and its nomenclature are shown in Figure 2 and Table 4 , respectively. The concrete mixes are poured into their respective moulds of geometrically similar beams with three different sizes, each having a notch to depth ratio of 0.2 and span to depth ratio of 2.5 . In order to create a notch, a fine metal strip of $2 \mathrm{~mm}$ thickness was introduce during casting at center for different notch size. 
The rationale behind the selection of small, medium and large beams is to study the effect of specimen size on the fracture behavior by testing geometrically similar specimens as per the draft recommendation of the RILEM Technical Committee 89-FMT on fracture mechanics of Concrete RILEM [25]. Using this method, one can obtain a size effect plot, by which the size of the structure can be extrapolated to large structures like dams. The notch site is kept at the center of the beam under three point bending as recommended by RILEM [25]. While handling the specimens, great care is taken to prevent any falling or impact on the specimen.

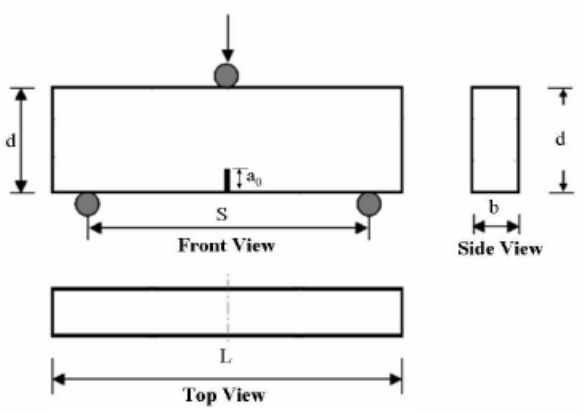

Figure 2: Details of geometry of the specimen

Table 2: Physical properties of sand and aggregates

\begin{tabular}{lccc}
\hline Properties & Sand & $\begin{array}{c}\text { Coarse } \\
\text { aggregate } \\
10 \mathrm{~mm} \\
\text { maximum } \\
\text { size }\end{array}$ & $\begin{array}{c}\text { Coarse } \\
\text { aggregate } \\
20 \mathrm{~mm} \\
\text { maximum } \\
\text { size }\end{array}$ \\
\hline $\begin{array}{l}\text { Specific } \\
\text { gravity }\end{array}$ & 2.62 & 2.8 & 2.78 \\
\hline $\begin{array}{l}\text { Bulk density } \\
\text { (Loose, }\end{array}$ & 1708 & 1450 & 1414 \\
$\left.\mathrm{~kg} / \mathrm{m}^{3}\right)$ & 1868 & 1652 & 1632 \\
\hline $\begin{array}{l}\text { Bulk density } \\
(\text { Compact, } \\
\left.\mathrm{kg} / \mathrm{m}^{3}\right)\end{array}$ & 180 & 0.56 \\
\hline $\begin{array}{l}\text { Water } \\
\text { absorption \% }\end{array}$ & 1.39 & 0.65 & \\
\hline
\end{tabular}

\subsection{Testing of specimens}

The specimens are tested in a closed loop servo-controlled testing machine having a capacity of $100 \mathrm{kN}$. A specially calibrated $50 \mathrm{kN}$ load cell is used for measuring the load. The load-point displacement is measured using a linear variable displacement transformer (LVDT). The crack mouth opening displacement (CMOD) is measured using a clip gage located across the notch. All the tests are performed under CMOD control with the rate of crack opening being $0.0005 \mathrm{~mm} / \mathrm{s}$. The results of load, vertical displacement, CMOD and time are simultaneously acquired through a data acquisition system.

Table 3: Composition of reference mix

\begin{tabular}{lc}
\hline Constituent & $\begin{array}{c}\text { Quantity } \\
\left(\mathrm{Kg} / \mathrm{m}^{3}\right)\end{array}$ \\
\hline Cement & 354 \\
\hline Fly ash & 96 \\
\hline Fine aggregate & 634 \\
\hline $\begin{array}{l}\text { Coarse aggregates } \\
(<10 \mathrm{~mm})\end{array}$ & 224 \\
\hline Coarse aggregates $(<20 \mathrm{~mm})$ & 332 \\
\hline Water & $160^{*}$ \\
\hline Superplasticiser & $2.225^{*}$ \\
\hline & $*$ is in liter
\end{tabular}

Table 4: Dimensions of beams

\begin{tabular}{lccc}
\hline Parameters & \multicolumn{3}{c}{ Beam designation } \\
\cline { 2 - 4 } & Small & Medium & Large \\
\hline Depth, d (mm) & 76 & 152 & 304 \\
\hline Span, S (mm) & 190 & 380 & 760 \\
\hline Length, L (mm) & 241 & 431 & 810 \\
\hline $\begin{array}{l}\text { Thickness, } \\
\text { b (mm) }\end{array}$ & 50 & 50 & 50 \\
\hline Notch depth, a $(\mathrm{mm})$ & 15.2 & 30.4 & 60.8 \\
\hline
\end{tabular}

For digital image correlation, the speckle pattern is to be made on the specimen. The specimens are initially white washed and a speckle pattern is prepared over it using a standard black spray paint. The images of the specimens are captured before loading and during various stages of loading using a digital camera mounted on a stand. A remote control is used for capturing the images to avoid any vibration and also to keep the distance between camera lens and the specimen unchanged. Further, it is known that a DIC measurement using a single camera introduces errors due to out-of-plane movements. The out-of plane 
movement may result in losing some of the information of the image part under consideration. The beam specimens are tested under three point bending and the supports as well as the loading cylinders are adjusted in such a way that the loading and reactions act in the plane of the specimen. Furthermore, the stiffness of the concrete specimens is relatively large to prevent any significant out-of-plane deformations. Hence, the out-of-plane movements are neglected in this work. It is assumed that a single image scale can be applied across the entire image to convert from imagespace coordinates to object-space coordinates.

\section{RESULTS AND DISCUSSIONS}

\subsection{Fresh properties}

The fresh properties of SCC are as important as its hardened properties. To evaluate workability of fresh self-compacting concrete like filling ability, passing ability and segregation resistance, different tests were carried out as per EFNARC [26] specifications. Filling ability of SCC was measured using a slump flow and a V-funnel test. Passing ability of SCC was measured using J- ring, L-box and U-box tests. Similarly resistance to segregation of self-compacting concrete was measured with the help of GTM Screen stability test. All test results are presented in Table 5.

It can be seen that addition of fibers reduce the flow and filling ability. Better flow properties were observed for mixes with lower volume fraction of fibers. Additions of steel fibers resist flow of SCC compared to glass fibers. The observed slump flow was $655 \mathrm{~mm}$ by addition steel fibers while it was $720 \mathrm{~mm}$ in case of addition of glass fibers. Similarly, Vfunnel flow values of $12 \mathrm{sec}$ and $9 \mathrm{sec}$ were observed in case of addition of steel fibers and glass fibers. Also, L Box and U Box test results show that additions of fibers in concrete give negative result on workability of SCC. But all results are within limit of EFNARC.

\subsection{Mechanical properties}

After conducting test for fresh properties, concrete was cast in cube, cylinder and beam
Table 5: Fresh properties of self-compacting concrete

\begin{tabular}{lccc}
\hline Workability test & \multicolumn{3}{c}{ Test Result } \\
\cline { 2 - 4 } & SCC & GFRSCC & SFRSCC \\
\hline $\begin{array}{l}\text { Slump Flow in } \\
\text { mm }\end{array}$ & 760 & 720 & 655 \\
\hline$T_{50}$ cm Slump & 4.2 & 4.4 & 4.8 \\
$\begin{array}{l}\text { Flow in Sec } \\
\text { J Ring }\end{array}$ & 6 & 7 & 10 \\
\hline $\begin{array}{l}\text { J Ring Flow in } \\
\text { mm }\end{array}$ & 730 & 700 & 610 \\
\hline $\begin{array}{l}\text { V-Funnel Flow } \\
\text { in Sec }\end{array}$ & 8 & 9 & 12 \\
\hline $\begin{array}{l}\text { L Box Blocking } \\
\text { Ratio }\end{array}$ & 0.93 & 0.88 & 0.82 \\
\hline $\begin{array}{l}\text { U Box Filling } \\
\text { Height }\end{array}$ & 20 & 23 & 28 \\
\hline
\end{tabular}

moulds for mechanical properties. Concrete cubes of dimension $150 \mathrm{~mm} \times 150 \mathrm{~mm} \times 150$ $\mathrm{mm}$ was cast and moist cured for 28 days. The compression test of concrete cube was performed as per IS 516 [27]. Cylinder of 150 $\mathrm{mm}$ dia. and $300 \mathrm{~mm}$ height was cast and tested for split tensile strength as per IS 516 [27]. Flexural strength of concrete was measured by testing of beam of size $100 \mathrm{~mm} \times 100 \mathrm{~mm} \times 500$ $\mathrm{mm}$ under four point bending test using Digital Universal Testing Machine with capacity of 60 ton. The results of compression test, split tensile strength and flexural strength of plain and fiber reinforced self-compacting concrete are presented in Table 6 .

Addition of $32 \mathrm{~kg} / \mathrm{m}^{3}$ hooked end steel fibers in SCC enhance compressive strength by $6.30 \%$, on other hand $1.45 \%$ increase in compressive strength was observed due to addition of $50 \mathrm{gm}$ per bag of cement glass fibers. Fibers lead to nominal increase in compressive strength but marginal increase in spilt tensile strength and flexural strength of selfcompacting concrete. Splitting tensile strength was increased by $31.36 \%$ while flexural strength was increased by $34.47 \%$ by addition of steel fibers in SCC. Similarly, $10.30 \%$ and $10.04 \%$ increase in split tensile strength and flexural strength respectively was observed in case of addition of glass fibers. 
Table 6: Hardened properties of self-compacting concrete

\begin{tabular}{lccc}
\hline $\begin{array}{l}\text { Type of } \\
\text { SCC }\end{array}$ & $\begin{array}{c}\text { Compressive } \\
\text { Strength } \\
(\mathrm{MPa})\end{array}$ & $\begin{array}{c}\text { Spilt } \\
\text { Tensile } \\
\text { Strength } \\
(\mathrm{MPa})\end{array}$ & $\begin{array}{c}\text { Flexural } \\
\text { Strength } \\
(\mathrm{MPa})\end{array}$ \\
\hline SCC & 62.64 & 4.56 & 4.38 \\
\hline GFR SCC & 63.53 & 5.03 & 4.82 \\
\hline SFR SCC & 66.59 & 5.99 & 5.89 \\
\hline
\end{tabular}

\subsection{Fracture tests}

Fracture test was conducted on closed loop servo-controlled testing machine under CMOD control with the rate of crack opening being $0.0005 \mathrm{~mm} / \mathrm{s}$ as shown in Figure 3. The load, CMOD and mid-span vertical displacement acquired during the test is analyzed. Figures 4 and 5 show the load versus mid-span vertical displacement and load versus CMOD curves, respectively for small, medium and large specimens plain specimens. Peak load for plain and fiber reinforced specimens are presented in Table 7. Results show that Peak load, displacement and CMOD was increased with increased in size of specimen.

It was also observed that in same size of specimens, there was slightly increase in peak load due to addition of fibers in SCC but energy absorption capacity (are under load displacement curve) was increased tremendously. Energy absorption capacity was increased by $198 \%$ and $1096 \%$ in small specimens, due to addition of glass fibers and steel fibers respectively.

Similarly in medium specimens, energy absorption capacity was increased by $184 \%$ and $614 \%$ due to addition of glass fibers and steel fibers respectively. Also, in case of large specimens, energy absorption capacity was increased by $104 \%$ and $407 \%$ due to addition of glass fibers and steel fibers respectively. It can be concluded that addition of fibers in specimens, increase the energy absorption capacity tremendously in all size of specimens.

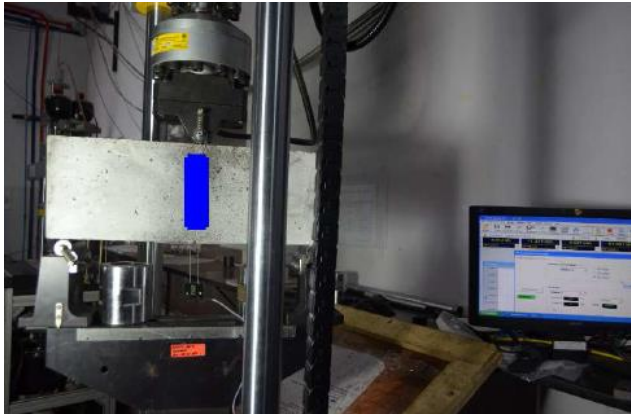

Figure 3: Fracture test set up and Grid pattern used for DIC analysis.

Table 7: Peak load of small, medium and large specimens in $\mathrm{kN}$

\begin{tabular}{llll}
\hline Type of SCC & Small & Medium & Large \\
\hline SCC & 4.43 & 6.68 & 11.70 \\
\hline GFRSCC & 4.43 & 6.70 & 11.88 \\
\hline SFRSCC & 4.45 & 6.91 & 12.30 \\
\hline
\end{tabular}

Table 8: Area under load displacement cureve for small, medium and large specimens in $\mathrm{kN} . \mathrm{mm}$

\begin{tabular}{lrrc}
\hline Type of SCC & Small & Medium & Large \\
\hline SCC & 0.53 & 1.71 & 5.06 \\
\hline GFR SCC & 1.58 & 4.86 & 10.34 \\
\hline SFR SCC & 6.34 & 12.21 & 25.69 \\
\hline
\end{tabular}

\subsection{Digital image correlation}

The digital images taken during the experiments for all the specimens are correlated using an algorithm originally written by Eberl et al. [28] using Matlab and suitably modified to suit our requirements. This software uses normalized cross-correlation algorithm with sub pixel resolution. The sub pixel displacement values are obtained through bilinear interpolation between pixels. The algorithm applies a cross-correlation function on two images before and after displacement and identifies the peak. The displacement is assumed to be at the location of the peak of the cross-correlation function. 


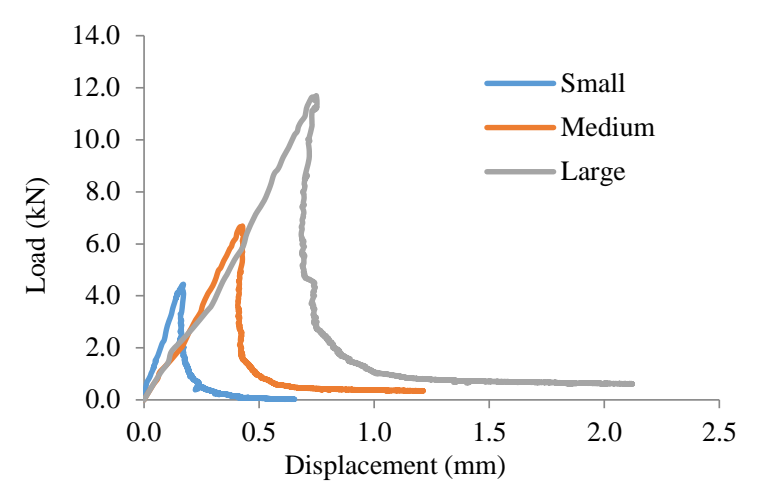

Figure 4: Load vs. Displacement curve (Plain SCC)

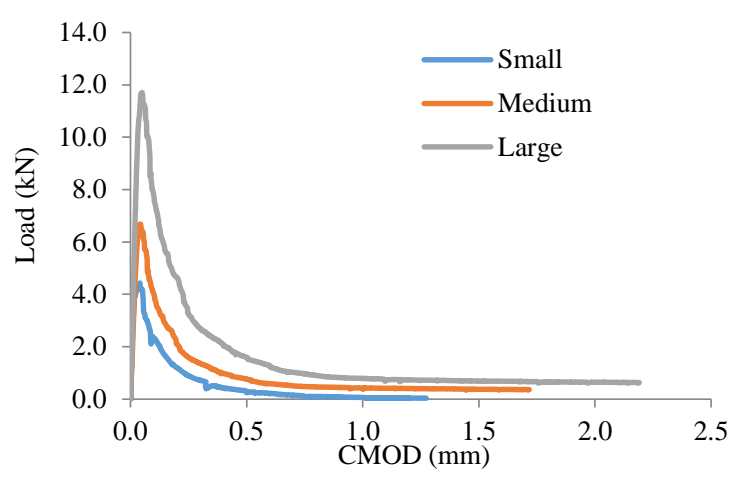

Figure 5: Load vs. CMOD curve (Plain SCC)

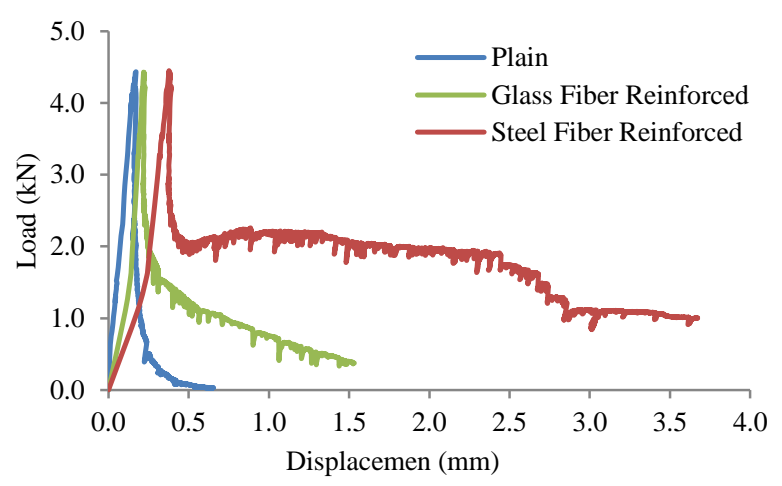

Figure 6: Load vs. Displacement curves for small specimens

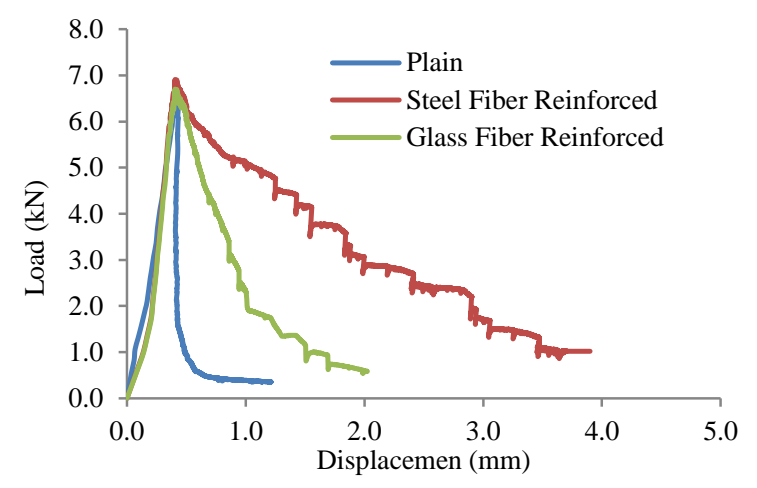

Figure 7: Load vs. Displacement curves for medium specimens

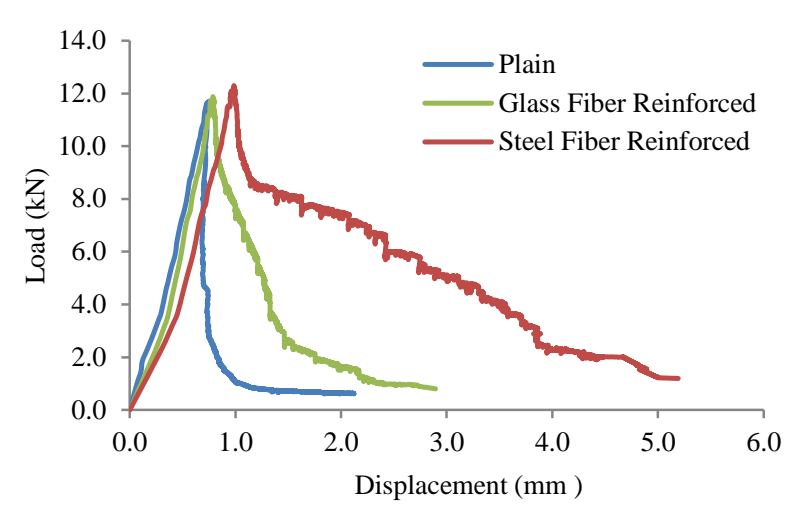

Figure 8: Load vs. Displacement curves for large specimens

Analysis was performed for selected beam. The central grid region is superposed on the specimen using the image correlation graphics. The displacements are computed in each of $\mathrm{x}$ and $y$ directions from within the central grid region. The accuracy of displacement is approximately 0.1 pixels on a point-to-point basis for translational movements. The accuracy of displacement obtained from DIC technique is dependent on the quality of speckle pattern, surrounding vibrations, lighting, out-of-plane displacements and gage length used for strain computations. Hence, it is difficult to give a general guideline for determination of strain accuracies. The results obtained from the DIC analysis of beams at different stages of loading are presented and discussed in this section.

\subsubsection{Displacements}

Figure 9 shows a three dimensional profile of the deformation taking place during different stages of loading. This figure shows the opening of the crack as the test progresses (depicted by the increasing image number) and is used for quantifying the crack opening displacement which is discussed in Section 3.4.3. The results of the vertical displacement at a point close to the notch at the bottom center of the specimen computed by DIC analysis and also measured using an LVDT is shown in Figure 10. It is seen that there is a very good match between the vertical displacements computed using DIC and those measured experimentally using an LVDT. This indicates the effectiveness of the DIC technique. 

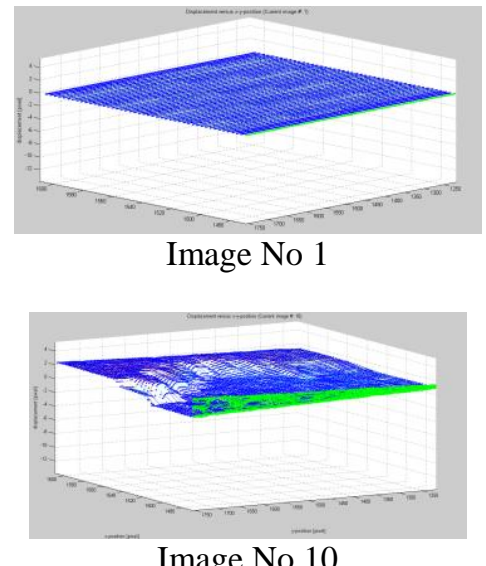

Image No 10

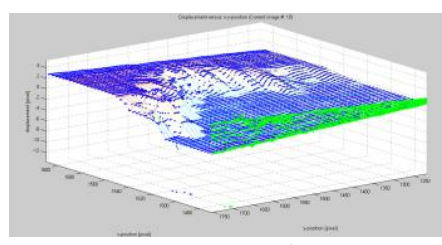

Image No 19

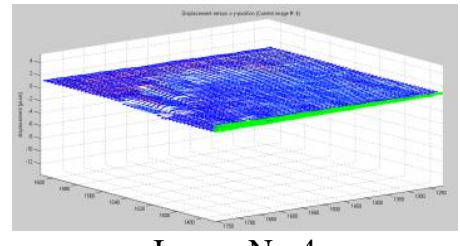

Image No 4

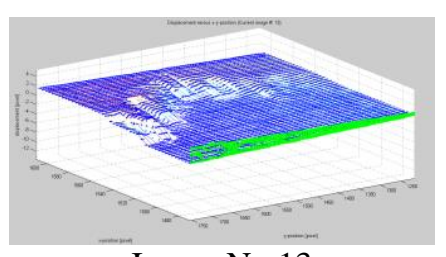

Image No 13

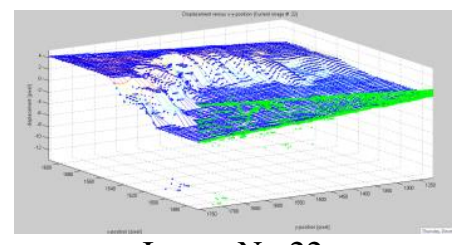

Image No 22
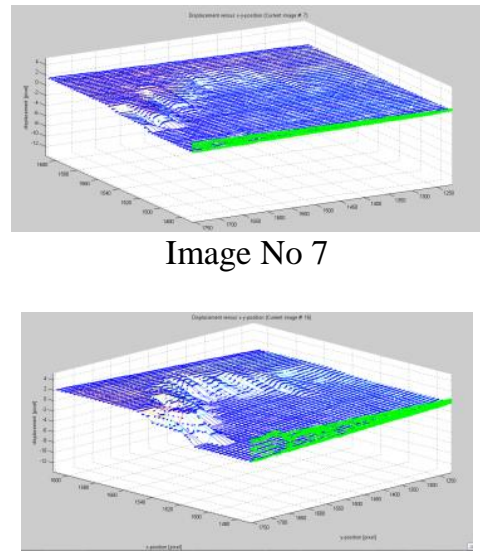

Image No 16

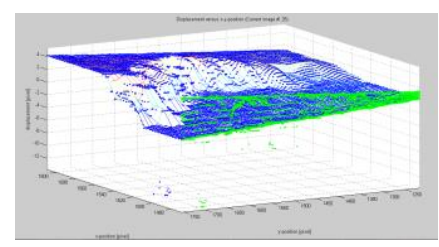

Image No 25
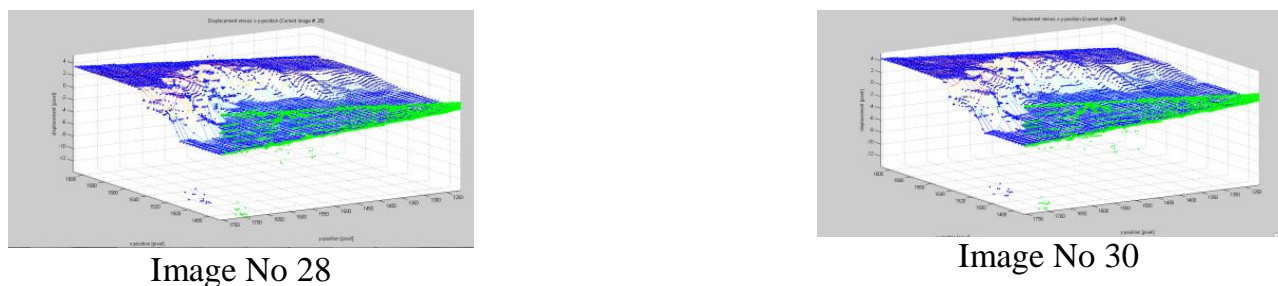

Figure 9: Three-dimensional displacement profile during different stages of loading (medium plain specimen)

\subsubsection{Crack length}

The method employed for determining crack opening displacement $(\delta x)$, crack tip location and the distance of crack tip ( $r$ ) from the digitally processed images is shown in Figure. 11 . The crack tip is located at a point where the crack opening displacement (COD) is zero through visual observation. The displacements are computed by considering a square grid (zone of interest) in each of $\mathrm{x}$ and $\mathrm{y}$ directions from within the central grid region. Since the crack tip is located with a precision equal to the size of the correlation window, the crack lengths are resolved to an accuracy of \pm 1.25 $\mathrm{mm}$. The crack lengths are computed for all the images and are plotted as shown in Figure 12.

This feature of obtaining the crack tip location and determination of crack length makes the DIC technique very attractive as it is very difficult to obtain these parameters through other methods. A technique such as dye penetration [29] for determination of the crack length has been reported in the literature and is difficult in terms of usage in addition to being expensive too.

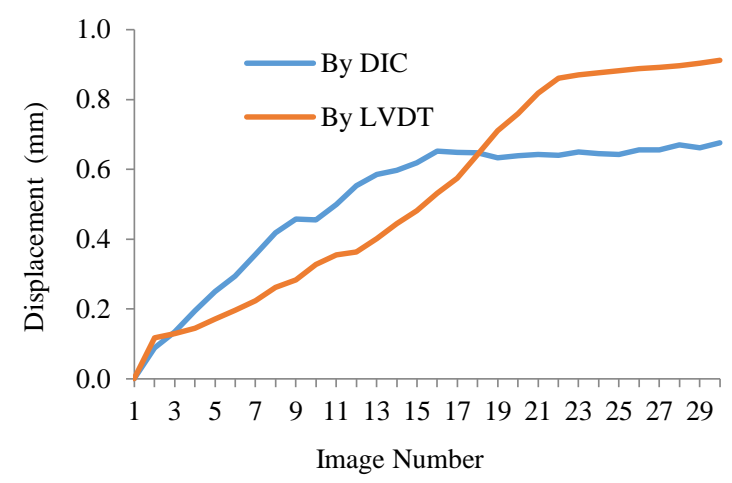

Figure 10: Displacement vs. Image number (medium plain specimen). 


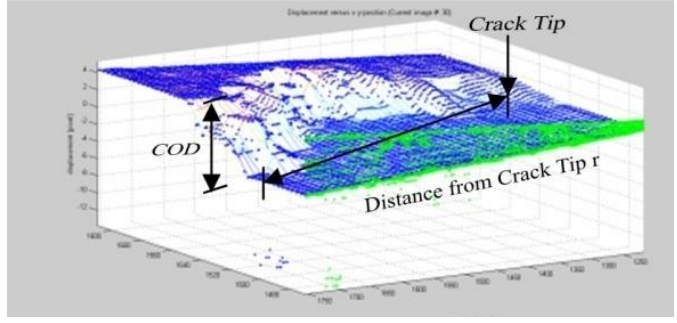

Figure 11: Crack opening displacements and crack length (medium plain specimen)

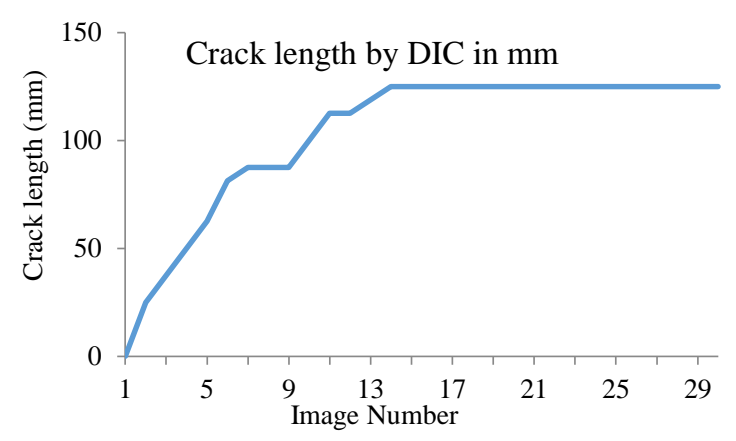

Figure 12: Crack length vs. Image number

\subsubsection{Crack mouth opening displacement and crack sliding displacement}

The advantage of DIC technique is that we can determine the crack opening displacement at any position along the crack, which is not possible with other experimental sensors such as, a clip gage, unless we mount a number of them along the crack. For validation of the results obtained from DIC, the CMOD computed for all the images using DIC analysis are plotted and compared with those measured experimentally using clip gage, as shown in Figure 13. It is seen that there is a very close match between the two. However, one drawback of DIC analysis seen is that the measurement of CMOD during the initial loading portion is difficult since the crack does not get initiated as seen from the results of images 1 to 4. While the CMOD gage is fixed at the central position along the thickness of the specimen, the DIC measurements are done on the surface. The crack openings are captured by the CMOD gage which does not get transferred on to the surface during the initiation phase of the crack. This may be the possible reason for the above mentioned drawback of the DIC. The accuracy of crack mouth opening and crack sliding displacements is approximately 0.1 pixels.

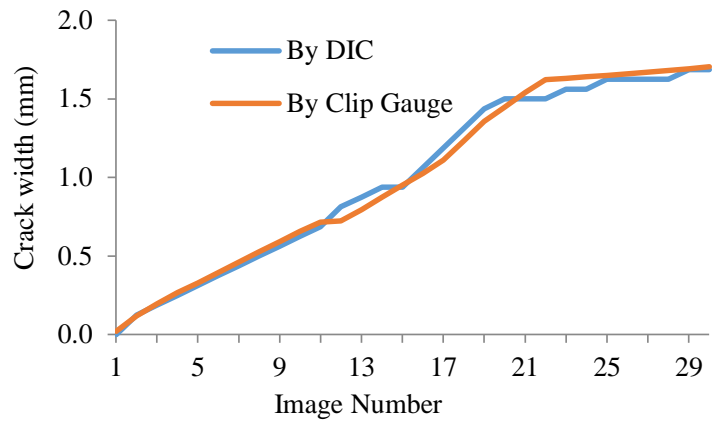

Figure 13: Crack width vs. Image number

\subsection{Brittleness number}

The brittleness number is characterizing the nature of failure regardless of structure geometry. This brittleness number is defined as

$$
\beta=\frac{d}{d_{0}}
$$

where $\mathrm{d}$ is depth of specimen and $d_{0}$ is an empirical constant. Brittleness number is calculated as per procedure describe in Shah S.G. and Chandra Kishen J.M. [30]. Results of brittleness number is presented in Table 9.

Plain, glass fiber reinforced and steel fiber reinforced self-compacting concrete follows Bazant's size effect law. Behavior of large specimens is more similar to linear elastic fracture mechanics (LEFM) graph which is for brittle material. It was also observed that all the specimens have the brittleness value between 0.1 and 10 which validate the applicability of the nonlinear fracture parameter. Figure 14 represent that all the data points lie in the transition zone between the LEFM criterion and the strength criterion. As size of specimens decrease, this behavior is similar to strength criterion.

Table 9: Brittleness Number

\begin{tabular}{|c|c|c|c|}
\hline \multirow{2}{*}{$\begin{array}{c}\text { Beam } \\
\begin{array}{c}\text { Designat } \\
\text { ion }\end{array}\end{array}$} & \multicolumn{3}{|c|}{$\beta=$ Brittleness Number } \\
\cline { 2 - 4 } & $\begin{array}{c}\text { Plain } \\
\text { Concrete }\end{array}$ & $\begin{array}{c}\text { Glass } \\
\text { Fiber } \\
\text { Reinforced }\end{array}$ & $\begin{array}{c}\text { Steel } \\
\text { Fiber } \\
\text { Reinforce } \\
\mathrm{d}\end{array}$ \\
\hline Small & 2.317 & 1.153 & 1.046 \\
\hline Medium & 4.635 & 2.305 & 2.091 \\
\hline Large & 9.269 & 4.610 & 4.182 \\
\hline
\end{tabular}




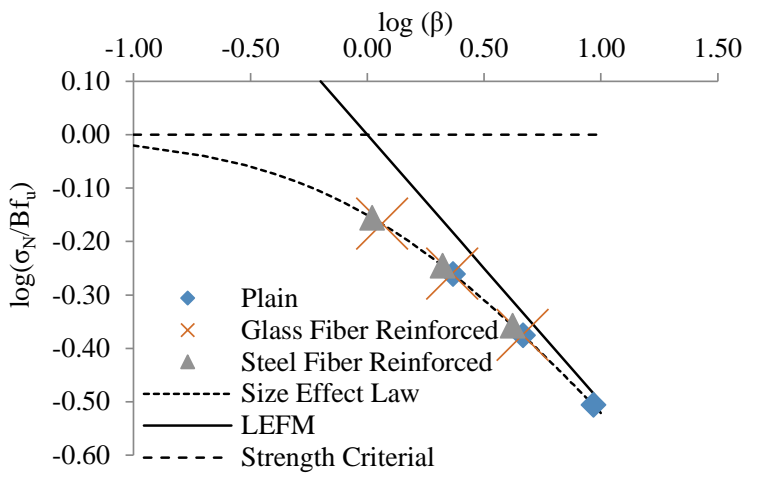

Figure 14: Experimental data following size effect law.

SCC with steel fibers (Brittleness number $=$ 2.440) behave much better than that of glass fibers (Brittleness number $=2.689$ ). Both SCC with steel and glass fibers behave better than plain SCC (without fiber) because brittleness number of plain SCC $(\beta=5.407)$ is less than that of SCC with fiber.

\section{CONCLUSIONS}

The following conclusions are drawn based on the present study.

- Addition of fibers in SCC gives negative impact on workability. SCC having steel fibers are les workable as compared to polyester and glass fibers, still all test results lies within EFNARC limit for all workability test.

- Fibers lead to nominal increase in compressive strength but marginal increase in split tensile and flexural strength of selfcompacting concrete. Addition of steel fibers, marginal increase in splitting and flexural strength of SCC, compared to polyester and glass fibers.

- Peak load, Displacement and CMOD was increased with increase in size of specimen.

- For the same size of specimens, there was a slight increase in peak load due to addition of fibers in to SCC but energy absorption capacity (are under load displacement curve) was increased tremendously.

- A good agreement is obtained in the vertical displacements and crack mouth opening displacements computed through DIC and those measured using LVDT and clip gage, respectively.
- It can be concluded that the simple DIC technique can be a very useful and an economical substitute for clip gages and LVDTs.

- The measurement of crack tip location and crack length can be done effectively using DIC techniques which are very difficult and expensive for concrete like materials using traditional sensors.

\section{REFERENCES}

[1] Erdem, T.K., Khayat, K.H., and Yahia, A. 2009. Correlating rheology of selfconsolidating concrete to corresponding concrete-equivalent mortar. ACI Materials Journal. 106(2):154160.

[2] Gaimster, R., and Dixon, N. 2003. Selfcompacting concrete Technology. In: Newman J, Choo BS, editors. Advanced concrete technology set. Oxford: Butterworth-Heinemann, 1-23.

[3] Najm, HS. (2008). "Specialized construction applications". In: Nawy EG, editor. Concrete construction engineering handbook. Boca Raton: CRC Press, 1-26.

[4] Skarendal, A. 2005. Changing concrete construction through use of selfcompacting concrete. Proceedings PRO 42 - 1st international symposium on design, performance and use of selfconsolidating concrete, SCC, China, 1724.

[5] Lava, P., Cooreman, S., and Debruyne, D. 2010. Study of systematic errors in strain fields obtained via DIC using heterogeneous deformation generated by plastic FEA. Opt. Lasers Eng, 48(4):457468.

[6] Zhang, H., Huang, G.Y., Song, H.P., and Kang, Y.L. 2012. Experimental investigation of deformation and failure mechanisms in rock under indentation by digital image correlation. Eng. Fract. Mech, 96: 667-675.

[7] Chen, J.L., Zhan, N., Zhang, X.C., and Wang, J.X. 2015. Improved extended digital image correlation for crack tip deformation measurement. Opt. Lasers Eng, 65: 103-109. 
[8] Wang, X., and Ma, S.P. 2014. Mesh-based digital image correlation method using nonuniform elements for measuring displacement fields with high gradient. Exp. Mech, 54:1545-1554.

[9] Huang, J.Y., Deng, H., Peng, X.L., Li, S.S., Xiong, C.Y., and Fang, J. 2012. Cellular traction force reconstruction based on a self-adaptive filtering scheme. Cell Mol. Bioeng, 2:205-216.

[10] Zhang, D.S., and Arola, D.D. 2004. Applications of digital image correlation to biological tissues. J. Biomed Opt, 9:691-699.

[11] Huang, J.Y., Pan, X.C., Peng, X.L., Zhu, T., Qin, L., Xiong, C.Y., and Fang, J. 2010a. High-efficiency cell substrate displacement acquisition via digital image correlation method using basis functions. Opt. Laser Eng, 48(11): 1058-1066.

[12] Huang, J.Y., Zhu, T., Pan, X.C., Qin, L., Peng, X.L., Xiong, C.Y., and Fang, J. 2010b. A high-efficiency digital image correlation method based on a fast recursive scheme. Meas. Sci. Technol, 21: 1-12.

[13] Debella-Gilo., Kaab, M.A. 2011. Subpixel precision image matching for measuring surface displacements on mass movements using normalized cross correlation. Remote Sens. Environ, 115: 130-142.

[14] Walter, T. R. 2011. Low cost volcano deformation monitoring optical strain measurement and application to Mount St. Helens data. Geophys. J. Int, 186:699705.

[15] Sutton, M.A., Orteu, J.J., and Schreier, H.W. 2009. Image correlation for shape, motion and deformation measurements. Springer, New York.

[16] Wang, Z.Y., Kieu, H., Ngugen, H., and Le, H. 2015. "Digital image correlation in experimental mechanics and image registration in computer vision: similarities, differences and complements. Opt. Lasers Eng, 65:18-27.

[17] Zhu, R.H., Xie, H.M., Hu, Z.X., Jiang, L.B., Guo, B.Q., and Li, C.W. 2015. Performances of different subset shapes and control points in subset-based digital image correlation and their applications in boundary deformation measurement. Appl. Opt, 54 (6):1290-1301.

[18] Zhou, Y.H., Sun, C, and Chen, J.B. 2014. Adaptive subset offset for systematic error reduction in incremental digital image correlation. Opt. Lasers Eng. 55:5-11.

[19] Wang, Z.Z., Wang, S.B., and Wang, Z.Y. 2014. An analysis on computational load of DIC based on Newton-Raphson scheme. Opt. Lasers Eng, 52:61-65.

[20] Dai, X.J., Yang, F.J., Chen, Z.N., Shao, X.X., and He, X.Y. 2015. Strain field estimation based on digital image correlation and radial basis function. Opt. Lasers Eng, 65: 64-72.

[21] Sutton, M.A., Wolters, W.J., Peters, W.H., Ranson, W.F., and McNeill, S.R. 1983. Determination of displacements using an improved digital correlation method. Image Vis. Comput, 1:133-139.

[22] Sutton, M.A., Cheng, M., Peters, W.H., Chao, Y.J., and McNeill, S.R. 1986. Application of an optimized digital correlation method to planar deformation analysis. Image Vis. Comput, 4: 143-150.

[23] Touchal, S.M., Morestin, F., and Brunet, M. 1997. Various experimental applications of digital image correlation method. Proceedings of international conference on computational methods and experimental measurements, Rhodes, Greece, 45-58.

[24] Bruck, H.A., McNeill, S.R., Sutton M.A., and Peters, W.H. 1989. Digital image correlation using Newton-Raphson method of partial differential correction. Exp. Mech., 29: 261-267.

[25] RILEM TC 89-FMT.1990. Size-effect method for determining fracture energy and process zone size of concrete. Mataterial and Structrcture, 23: 461-465.

[26] EFNARC. 2002. Specification and guidelines for self-compacting concrete. European association for producers and applicators of specialist building products, UK.

[27] IS-516. 1999. Methods of tests for strength of concrete. Bureau of Indian Standards, New Delhi. 
[28] Eberl, C., Thompson, R., and Gianola, D. 2006. Digital image correlation and tracking with Matlab.

http://www.mathworks.com/matlabcentral/ fileexchange/12413.

[29] Swartz, S.E., and Refai, T. 1989. Cracked surface revealed by dye and its utility in determining fracture parameters. In: Mihashi H. et al (eds) Fracture toughness and fracture energy: test methods for concrete and rock. Balkema, Brookfield, 509-520.

[30] Shah, S.G. and - Chandra Kishen, J.M. Nonlinear fracture properties of concreteconcrete interfaces. Mechanics of Materials, 42 (2010) 916-931 